\title{
Organização retórica do resumo acadêmico gráfico: um gênero acadêmico multimodal
}

\section{Rhetorical organization of academic graphical abstracts: a multimodal academic genre}

Cristiane Salete Florek

Universidade Federal de Santa Maria, Santa Maria, Rio Grande do Sul / Brasil crisflorek@hotmail.com

Resumo: Este artigo relata a investigação do resumo acadêmico gráfico (RAG), prática discursiva multimodal típica de certas áreas do contexto acadêmico. Metodologicamente, empregou-se a Análise Crítica de Gênero (MEURER, 2002; BHATIA, 2004; MOTTA-ROTH, 2006, 2008) a fim de analisar as características textuais e contextuais de 40 RAGs de Química e de Biologia e descrever sua organização retórica prototípica. Para a análise textual, efetuaram-se: i) identificação, descrição e categorização dos significados dos modos semióticos verbal e visual (HALLIDAY; MATTHIESSEN, 2004; KRESS; VAN LEEUWEN, 2006); e ii) identificação de padrões retóricos recorrentes (SWALES, 1990). Para a análise contextual realizaram-se: i) entrevistas com pesquisadores das áreas investigadas; e ii) análise documental. Os resultados evidenciam que, embora o RAG apresente movimentos retóricos típicos de outros gêneros acadêmicos, é um novo gênero, que coloca em proeminência o modo semiótico visual. Essa característica o diferencia do resumo acadêmico, pois potencializa o multipropósito comunicativo de atrair o leitor e sintetizar a pesquisa reportada em um artigo. Isso responde à recorrente necessidade da comunidade científica de otimizar o tempo de busca e de seleção de artigos acadêmicos para leitura e, especialmente, de destacar e otimizar a divulgação dos resultados da pesquisa científica. 
Este trabalho defende que o estudo crítico e multimodal de RAGs possibilita interpretar os novos discursos disponíveis no contexto acadêmico, auxiliando na proposição de meios pedagógicos em prol dos multiletramentos (THE NEW LONDON GROUP, 1996).

Palavras-chave: resumo acadêmico gráfico; Análise Crítica de Gênero; organização retórica.

Abstract: This paper reports an investigation about academic graphical abstract (AGA), typical multimodal discursive practice from certain areas of academic context. Methodologically, we employed the Genre Critical Analysis (MEURER, 2002; BHATIA, 2004; MOTTA-ROTH, 2006, 2008) to investigate the textual and contextual features of forty AGAs from Chemistry and Biology, and to describe its rhetoric prototypical organization. For textual analysis, we performed: i) identification, description and categorization of the meanings from verbal and visual semiotic modes (HALLIDAY; MATTHIESSEN, 2004; KRESS; VAN LEEUWEN, 2006); and ii) identification of recurrent rhetorical patterns (SWALES, 1990). For contextual analysis, we performed: i) interviews with researchers of the investigated areas; and ii) documental analysis. Our results showed that although the RAG presents typical rhetorical movements similar to other academic genres, it is a new genre that puts prominence on the visual semiotic mode. This feature differentiates AGA from academic abstracts, mainly because it enhances the multipurpose of attracting the reader and summarizing the research reported in an article. This ensures the recurring need of scientific community to save time during the search and selection of academic articles and optimize the dissemination of scientific research results. We believe that the critical and multimodal study of AGAs enables us to interpret new discourses nowadays available in the academic context, supporting teach methodologies in favor of multiliteracies (THE NEW LONDON GROUP, 1996).

Keywords: academic graphical abstract; Genre Critical Analysis; rhetorical organization.

Recebido em :15 de setembro de 2016.

Aprovado em: 28 de outubro de 2016. 


\section{Introdução}

A linguagem é uma tecnologia fundamental que usamos para nos expressar simbolicamente e, assim, construir ambientes retóricos onde assumimos diferentes identidades, interagimos e efetivamos as mais diversificadas atividades sociais em virtude da necessidade que temos de alcançar um propósito, comunicar algo a alguém, realizar uma ação em um dado momento e em um determinado contexto (SWALES, 1990). Embora pareça bastante lógico que esses espaços de interação humana são propulsores do desenvolvimento social, a maioria das pessoas não tem a mais vaga ideia das práticas sociais e discursivas subjacentes a eles (SNOW, 1995; LEMKE, 2002), por isso a importância de estudá-las de um ponto de vista linguístico (textual e contextual), no ensejo de aprimorar as práticas de ensino relacionadas à leitura e à escrita de textos típicos desses contextos, conduzindo ao empoderamento crítico do leitor / produtor de tais textos por meio da tomada de consciência dos condicionamentos ideológicos e das relações de poder que se estabelecem via linguagem.

Há algum tempo, no âmbito da Linguística Aplicada, dispomos de perspectivas teórico-metodológicas que entendem os diferentes usos da linguagem associados as mais variadas atividades sociais como gêneros discursivos com padrões recorrentes de realização e, por isso, com "algum grau de estabilidade na forma, no conteúdo e no estilo" (MOTTA-ROTH, 2008, p. 350). Além de colocarem os gêneros discursivos e os contextos sociais em que são praticados em seu foco de análise, tais perspectivas (MEURER, 2002; BHATIA, 2004; MOTTAROTH, 2006, 2008) ressaltam a natureza inevitavelmente multimodal dos gêneros discursivos (THE NEW LONDON GROUP, 1996; KRESS; VAN LEEUWEN, 1996, 2006), que, cada vez mais, apresentam a combinação de diferentes recursos semióticos (verbal, visual, sonoro, gestual, p. ex.).

Os gêneros discursivos, ainda que apresentem padrões retóricos recorrentes e relativamente estáveis (SWALES, 1990), não são estáticos ou imutáveis, pelo contrário, estão em constante processo de evolução e transformação (MILLER, C., 1984; BAZERMAN, 1988; SWALES, 1990; BHATIA, 1993), assim como os contextos sociais aos quais imprimem materialidade. Algumas das transformações recentes observadas dizem respeito à presença cada vez maior do modo semiótico visual em gêneros em que a linguagem verbal (escrita) tradicionalmente prevalecia (p. ex.: manuais de instruções, resumos acadêmicos, bulas de remédio) (UNSWORTH, 2001; KNOX, 2007; 
2009). Especialmente em gêneros acadêmicos, os recursos semióticos visuais são reconhecidamente eficientes para comunicar ideias, relatar resultados, representar metodologias e demonstrar relações de forma concisa e atrativa (BAZERMAN, 1988; SWALES, 1990; MYERS, 1990; MILLER, T., 1998), ainda que, segundo Hendges (2007), seu papel, importância e ocorrência varie de uma área de conhecimento para a outra.

É no contexto acadêmico, nos Sumários online (Table of Contents) de periódicos científicos de alto fator de impacto, principalmente das áreas de Química e de Biologia, que se encontra com maior frequência nosso objeto de estudo: o resumo acadêmico gráfico (em inglês, Graphical Abstract) (PÉREZ-LLANTADA, 2013; FLOREK; HENDGES, 2013; FLOREK, 2015; LANE; KARATSOLIS; BUI, 2015). ${ }^{1}$ Em estudos prévios (FLOREK; HENDGES, 2013; FLOREK, 2015), denominamos essa prática discursiva de resumo acadêmico gráfico (RAG) por compartilhar espaço com outro gênero acadêmico, o tradicional resumo acadêmico, sumarizando as principais informações de um gênero acadêmico mais extenso, o artigo acadêmico, e por apresentar uma composição com destaque para imagens, figuras e gráficos.

Em termos práticos, como já viemos indicando, entendemos que estudar o RAG no âmbito da Linguística Aplicada requer criar inteligibilidade sobre o contexto social em que essa prática tem papel central (MOITA LOPES, 2006), transcendendo, para tanto, os limites da Linguística como componente teórico principal do estudo e propondo um trabalho com as epistemologias de fronteira (MOTTA-ROTH, 2003; MOITA LOPES, 2011). É nesse sentido, que neste artigo, pretendemos relatar a pesquisa realizada com RAGs de Química e de Biologia, ${ }^{2}$ tendo

\footnotetext{
${ }^{1}$ Embora a prática de RAGs não seja recente - sua primeira aparição ocorreu em 1976, na versão alemã do periódico científico Angewandte Chemie - foi a partir de 2009, no âmbito do projeto Artigo do Futuro, proposto pela editora Elsevier (2009), que o RAG passou a figurar em alguns periódicos científicos dessa editora e, paulatinamente, vem ocorrendo em periódicos científicos de outras editoras, como Nature, por exemplo.

2 A pesquisa aqui relatada vem sendo desenvolvida desde 2013, sob orientação da Profa. Dra. Graciela Rabuske Hendges, no Laboratório de Pesquisa e Ensino de Leitura e Redação (LABLER), do Programa de Pós-Graduação em Letras, da Universidade Federal de Santa Maria. Gostaríamos, portanto, de materializar nosso agradecimento especial à professora orientadora desta pesquisa, aos colegas de Mestrado e, atualmente, de Doutorado, à banca examinadora da Dissertação de Mestrado, que contribuíram e continuam contribuindo de diversas maneiras para a articulação e execução desta pesquisa.
} 
por base a Análise Crítica de Gênero (ACG) (MEURER, 2002; BHATIA, 2004; MOTTA-ROTH, 2006; 2008), conforme detalhamos na seção a seguir.

\section{Um aporte teórico-metodológico mestiço para a análise crítica de gêneros discursivos}

AACG é uma perspectiva teórico-metodológica mestiça que alia, conforme explica Motta-Roth (2008), os pressupostos da Linguística Sistêmico-Funcional (LSF) (HALLIDAY; HASAN, 1989; HALLIDAY, 1994; HALLIDAY; MATTHIESSEN, 2004) à Análise Crítica do Discurso (ACD) (FAIRCLOUGH, 1989, 1992) e à Sociorretórica (MILLER, C., 1984; SWALES, 1990; BHATIA, 1993), oferecendo procedimentos e categorias de análise para a investigação de um texto com foco em seu contexto. Além disso, uma vez que a LSF e a ACD servem de referência para a Análise do Discurso Multimodal (ADM) (O'TOOLE, 1994; KRESS; VAN LEEUWEN, 1996, 2006; O'HALLORAN, 2004; VAN LEEUWEN, 2008), entendemos que ela também compõe o quadro da ACG, nos permitindo investigar gêneros multimodais, especialmente os que congregam recursos semióticos visuais estáticos e verbais escritos.

Em linhas gerais, para os fins deste estudo, a LSF e a ADM nos permitem investigar, em uma perspectiva sociossemiótica e multifuncional, como, por meio da linguagem: i) codificamos a nossa vivência e experiência do mundo (metafunção ideacional / representacional); ii) codificamos atitudes, interações e relações sociais estabelecidas via linguagem (metafunção interpessoal / interativa); e iii) codificamos significados de desenvolvimento textual e organização retórica (metafunção textual / composicional).

Além disso, a Gramática Sistêmico-Funcional, decorrente da LSF, nos aporta o entendimento de que a linguagem verbal pode ser analisada desde seus estratos mais nucleares, como fonologia e grafologia, lexicogramática e semântica e pragmática, até seus níveis mais externos, como contexto de situação e contexto de cultura. Hendges, Nascimento e Marques (2013) destacam que, no âmbito da ADM, a Gramática do Design Visual (KRESS; VAN LEEUWEN, 2006), enquanto ferramental teórico que descreve o modo semiótico visual, traz à tona o fato de que, assim como a linguagem verbal, a linguagem visual também possui 
estruturas equivalentes ao que denominamos lexicogramática e que formam, portanto, uma gramática.

A ACD contribui para este estudo no sentido de aportar uma dimensão linguisticamente orientada e também crítica de análise. À luz da $\mathrm{ACD}$, os textos são considerados eventos discursivos (a materialização dos discursos), e os discursos são entendidos como a "linguagem em uso, como uma forma de prática social em vez de uma atividade puramente individual ou um reflexo das variáveis situacionais" (FAIRCLOUGH, 1992, p. 63). Segundo Meurer (2005, p. 95), o entendimento do discurso implica três níveis de análise: a descrição do texto enquanto evento discurso, a interpretação das práticas discursivas adjacentes ao texto e a explicação do texto à luz das práticas sociais. A descrição do evento discursivo enquanto texto solicita a análise dos elementos formais do texto (léxico, gramática, coesão e coerência) (MEURER, 2005, p. 95). A análise interpretativa, a partir do contexto de produção e de consumo do texto, considera a força (atos de fala), coerência, intertextualidade e interdiscursividade do texto, contra o pano de fundo da prática discursiva (MEURER, 2005, p. 95). Por fim, a investigação do discurso como prática social procura explicar as ideologias (significações/construções da realidade) e hegemonias (poder sobre a sociedade) veiculadas via discurso (FAIRCLOUGH, 1992).

Para os fins deste estudo, a Sociorretórica aporta embasamento teórico-metodológico para a identificação das regularidades retóricas do RAG de acordo com seus propósitos comunicativos no seio da(s) comunidade(s) discursiva(s) que o pratica(m), visto que os estudos desenvolvidos à luz da Sociorretórica abordam a retórica como um critério pragmático importante para a definição dos gêneros (MILLER, C., 1984). Tais estudos investigam como os gêneros, enquanto ação social (MILLER, C., 1984), "capacitam os usuários para realizar retórica e linguisticamente ações simbólicas situadas e, ao fazer isso, desempenhar ações e relações sociais, cumprir papéis sociais e moldar realidades" (BAWARSHI; REIFF, 2013, p. 81).

Em síntese, a ACG nos permite, por meio dos conceitos da LSF e da ADM, investigar as estruturas mínimas dos modos semióticos verbal e visual que compõem o RAG. Os conceitos da Sociorretórica nos permitem investigar as funções realizadas pelo contexto e pelos modos semióticos que integram o RAG e, assim, estabelecer a organização retórica do texto que resulta da intersecção desses modos semióticos 
em um contexto social específico. A ACD oferece a possibilidade de investigar o RAG criticamente contra o pano de fundo do momento histórico a que pertence (MOTTA-ROTH, 2008). Na próxima seção, relatamos como essas teorias e as categorias de análise propostas por elas foram arranjadas metodologicamente para analisarmos RAGs das áreas de Química e de Biologia.

\section{Metodologia}

Nesta seção, primeiramente, apresentamos o universo de análise da pesquisa. Em seguida, caracterizamos os corpora sobre os quais nos debruçamos, e, por fim, explanamos como sistematizamos os procedimentos e as categorias de análise oferecidos pela ACG para analisarmos o texto e o contexto de RAGs.

O universo de análise desta pesquisa compreende: i) duas áreas do conhecimento: Biodiversidade e Química, conforme estabelecido pela Coordenação de Aperfeiçoamento de Pessoal de Nível Superior (CAPES, 2014a); ${ }^{3}$ ii) quatro diferentes periódicos científicos e documentos sobre a produção e o consumo de RAGs a eles atrelados: 1) Angewandte Chemie; 2) Energy and Environmental Science; 3) Nature Chemical Biology; e 4) Journal of Controlled Release, selecionados como representativos das áreas de Química e de Biologia por apresentar Qualis A1 (CAPES, 2014b) e elevado fator de impacto (conf. base de dados do Journal Citation Reports - JCR) (WEB OF KNOWLEDGE, 2016); e11 pesquisadores (4 de Química e 7 de Biodiversidade) da Universidade Federal de Santa Mairia (UFSM), escolhidos por integrarem Programas de Pós-Graduação reconhecidos dentro de suas áreas (PRPGP/UFSM, 2013).

É importante destacar que, ao cruzarmos as informações sobre os periódicos científicos com maior fator de impacto e Qualis A1 em cada uma das área investigadas, Energy and Environmental Science e Angewandte Chemie apresentaram classificação de Fator de Impacto e de Qualis unicamente para a Área de Química, enquanto Nature

\footnotetext{
${ }^{3}$ A escolha da Área de Química satisfez o critério de pioneirismo, uma vez que essa área foi a precursora na prática do RAG (NATURE, 2011), expandindo-a, ao longo dos anos, na própria área de Química e para outras áreas. A escolha da Área de Biodiversidade ocorreu com base na observação assistemática das práticas de pesquisadores do campo de Ciências Biológicas, favorecida pela proximidade pessoal com pesquisadores da área.
} 
Chemical Biology e Journal of Controlled Release, que apareceram como mais representativos da área de Biodiversidade, também apresentaram qualificações para a área de Química, podendo ser classificados, portanto, como interdisciplinares (CAPES, 2012).

Este estudo investiga dois corpora, um textual e outro contextual. O corpus textual é composto de 40 RAGs (sendo 20 da Química e 20 interdisciplinares Química/Biologia) de artigos acadêmicos experimentais, coletados de cada um dos dez números de cada periódico científico selecionado para esta pesquisa até março de 2014. Para sistematizar a coleta do RAG em cada número de cada periódico científico, escolhemos o quinto da lista no Sumário, desde que pertencente à seção de artigos acadêmicos experimentais.

$\mathrm{O}$ corpus contextual desta pesquisa, referente à produção e ao consumo de RAGs, contou com: i) 11 entrevistas semiestruturadas: ${ }^{4}$ realizadas com pesquisadores das áreas de Química e de Biodiversidade, da Universidade Federal de Santa Maria, em encontros presenciais ou via e-mail, conforme acordo prévio (as entrevistas foram estruturadas em três partes que buscaram informações sobre os dados de identificação, de formação e de produção do pesquisador; impressões do pesquisador sobre a prática do RAG em seu campo de atuação; e conhecimentos sobre a função, conteúdo proposicional, aspectos formais, público-alvo e trajetória de leitura do RAG); e ii) análise documental: efetivada com base nas Instruções para autores e nos Sumários dos periódicos científicos escolhidos para a pesquisa.

Os procedimentos e as categorias de análise empregados na pesquisa que relatamos neste artigo tiveram origem na sistematização das três principais correntes teórico-metodológicas que fundamentam a ACG, quais sejam: LSF/GSF/ADM/GDV, Sociorretórica e ACD (Figura 1). Assim, examinamos os dados contextuais, referentes às formas de produção e de consumo do RAG, seguindo as categorias da LSF/GSF e, quando se fez necessário, da ADM/GDV. Da mesma forma, procedemos com os dados textuais, tomados como nosso evento discursivo. Cruzando esses dados, pudemos chegar ao entendimento, ainda que provisório, do contexto situacional em que se insere o gênero investigado (onde, quem e

\footnotetext{
${ }^{4}$ As entrevistas foram realizadas após devida aprovação do projeto Uma Análise Crítica de Resumos Acadêmicos Gráficos junto ao Comitê de Ética em Pesquisa (CEP) da UFSM, sob o n ${ }^{\circ} 24587813.0 .0000 .5346$.
} 
como pratica o RAG) e do contexto de cultura (com que propósito, em que âmbito discursivo, a par de quais outros gêneros, com quais recorrências retóricas) que lhe serve como pano de fundo. Esse cruzamento de dados nos possibilitou perceber a quais discursos e práticas sociais esse gênero dá materialidade, por quais motivos e como essas informações são organizadas no nível textual.

FIGURA 1 - Categorias analíticas para a investigação de gêneros que congregam recursos semióticos visuais e verbais, conforme pressupostos da Análise Crítica de Gênero

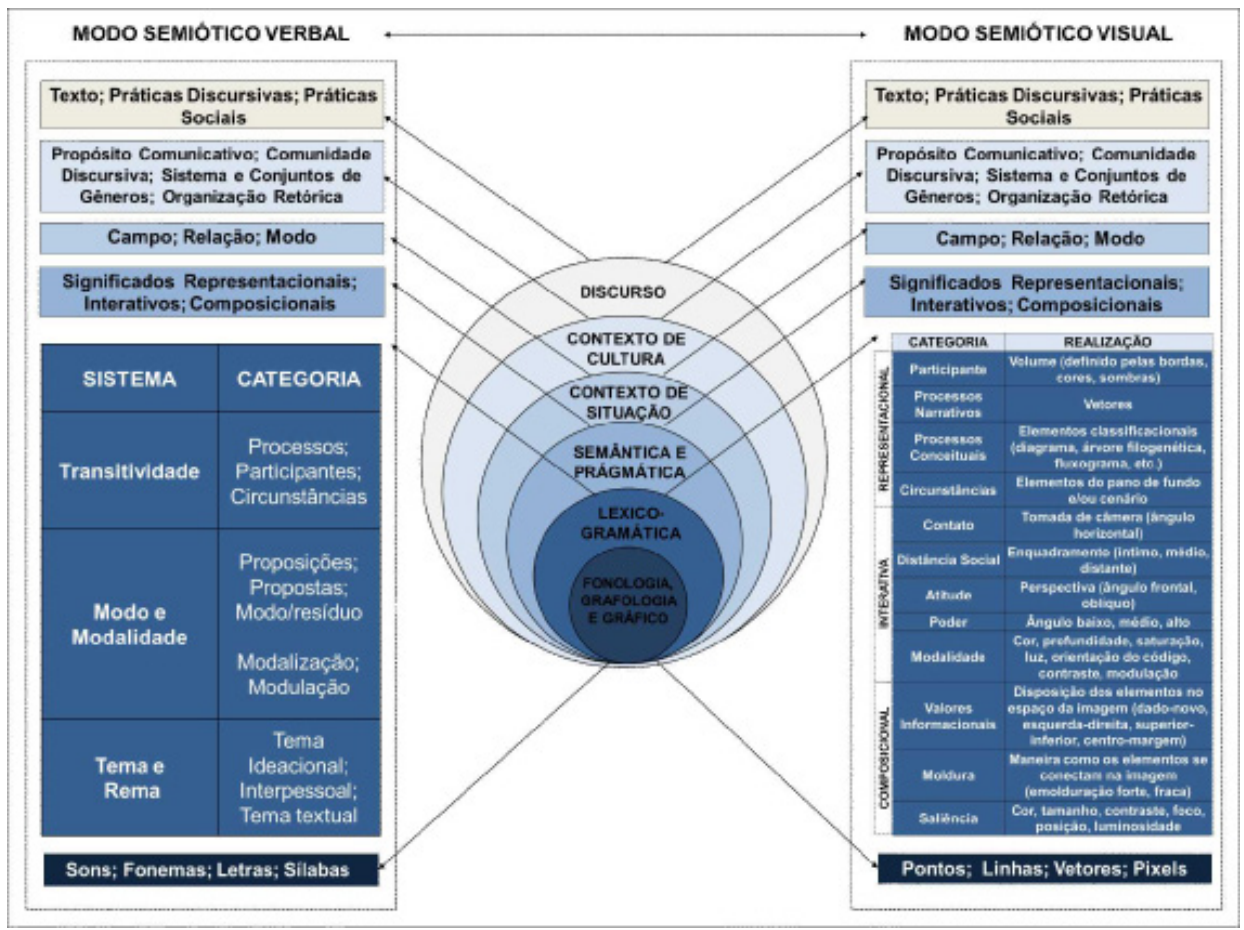

Fonte: Elaborado pela autora

\section{Resultados}

Nossa análise foi realizada em movimentos de tomada e retomada do texto e do contexto, no sentido de que um pudesse jogar luz sobre o outro (ASKEHAVE; SWALES, 2001). Por questões didáticas, 
apresentaremos primeiramente os resultados contextuais e posteriormente os resultados textuais encontrados. Por fim, com base no cruzamento desses resultados, apresentaremos nossas conclusões iniciais sobre a organização retórica prototípica do RAG.

\subsection{O que o contexto tem a informar sobre o RAG}

Expomos primeiramente os resultados obtidos com a investigação dos documentos atrelados à prática de RAGs nas áreas de Química e de Biodiversidade. Assim, começamos apresentando nossas conclusões sobre os Sumários dos periódicos científicos. Em seguida, expomos o resultado da análise das Instruções para autores e, finalizamos com a apresentação dos resultados obtidos por meio de entrevistas com os pesquisadores das duas áreas em foco.

A análise dos Sumários dos periódicos científicos, conforme pressupostos de Tenopir et al. (2013) em termos do que seja leitura no contexto acadêmico, nos revela que o RAG é um passo de pré-leitura do artigo acadêmico devido à sua posição de destaque no espaço do Sumário, materializada por recursos visuais de saliência, que, segundo van Leeuwen (1993) são importantes para definir o ponto de partida da leitura de um texto multimodal. Mesmo supondo que leitores/pesquisadores logocêntricos (que primam por informações de materialidade verbal escrita) possam desconsiderar o RAG como porta de entrada para as informações do artigo acadêmico, o layout dos Sumários dos periódicos indicam uma tendência à multimodalidade e nos levam a propor, com base em estudos prévios (TENOPIR et al., 2013) e nos resultados de nossas entrevistas, que o surgimento do RAG não imporia uma nova trajetória de leitura, mas seria um meio de legitimação de uma trajetória ou de uma prática de leitura que já existia e que vem ganhando força no contexto acadêmico.

Nesse sentido, as Instruções para autores de RAGs fornecem informações importantes para esclarecer os resultados obtidos na análise dos Sumários e auxiliar na definição da organização retórica prototípica de RAGs, pelo menos das áreas de Química e de Biologia. Na análise das Instruções para autores, encontramos oito tópicos recorrentes, os quais explanamos e discutimos a seguir.

De modo geral, as Instruções para autores assinalam a Obrigatoriedade de se publicar um resumo gráfico, definido como uma 
imagem colorida, ou um gráfico especialmente preparado para esse fim ou de destaque no trabalho, com a Finalidade de sumarizar visualmente o manuscrito, capturando a atenção a partir da curiosidade despertada sobre os aspectos inovadores do trabalho.

Quanto aos Recursos verbais, as Instruções para autores indicam a licença de uso de texto verbal escrito ou lembram sobre o limite permitido. Em termos de Recursos visuais, elas sugerem fortemente o seu uso, salientando a permissão de figuras coloridas, a não obrigatoriedade de a imagem compor o manuscrito e a permissão do uso de estruturas químicas ou fotografias.

Tais Instruções lembram ainda que o Local de Aparição típico do RAG é o Sumário dos periódicos científicos, mas que eles podem aparecer também na versão impressa e/ou online (HTML) do artigo acadêmico. Além disso, as instruções salientam que os RAGs não são exclusividade de artigos acadêmicos experimentais, podendo sumarizar, por exemplo, artigos teóricos, artigos de revisão (conf. classificação de SWALES, 2004), minereviews, news, highlights.

Sobre os Aspectos formais do RAG, as Instruções para autores oferecem informações sobre: i) o conteúdo representacional (p. ex., estruturas químicas, tema do trabalho, novidades da pesquisa); e ii) conteúdo composicional (p. ex., tamanho, disposição espacial, nitidez, contraste). Há instruções sobre o Modo de Envio do RAG, orientando ou para o envio no ato da submissão do manuscrito ou após a sua aceitação para publicação. A maioria das Instruções oferecem Exemplos de RAGs, os quais podem ser consultados nas próprias Instruções ou na versão online do periódico científico.

A investigação dos tópicos recorrentes das Instruções para autores nos aporta informações gerais relevantes para definições iniciais sobre a organização retórica do RAG. Primeiramente, notamos que a existência do RAG tem relação com as novas possibilidades de configuração e distribuição de periódicos e artigos científicos, facilitadas pela ascensão de novas tecnologias. Assim, os RAGs aparecem, principalmente, na versão HTML do artigo acadêmico ou se materializam na versão online dos periódicos científicos. Em termos de composição, esse gênero congrega pelo menos o modo semiótico verbal e o visual, com destaque para o visual (incentivando o uso de cores, por exemplo) e restrições para o verbal (limitando o uso de elementos verbais). Notamos, também, que em áreas como Biodiversidade e Química e, especialmente, em 
periódicos científicos de alto Fator de Impacto, os RAGs são obrigatórios, ou sua prática é fortemente sugerida. Com base nas diretrizes específicas quanto à apresentação das informações, principalmente em relação aos significados representacionais e composicionais, podemos inferir que o RAG possui a finalidade de sumarizar o tema ou as principais descobertas do artigo acadêmico, capturando a atenção de um largo número de leitores. Outras possíveis funções do RAG, como quanto à sua importância para a avaliação dos manuscritos ainda não são um consenso, tendo em vista o Modo de envio requerido pelos periódicos científicos. Por fim, com base no teor e detalhamento das Instruções para autores, podemos propor que o RAG não configura uma prática corriqueira ou consolidada no meio acadêmico em geral.

As entrevistas com pesquisadores das áreas de Química e de Biologia revelam que a prática do RAG é mais recorrente em Química (onde 100\% dos pesquisadores entrevistados responderam já ter produzido RAGs, contra $14 \%$ da área de Biodiversidade) e também mais expressiva, chegando à cifra de um RAG para cada dois artigos acadêmicos publicados por pesquisador.

Em linhas gerais, a maioria dos pesquisadores (90\%) indicou saber o que é um RAG e 64\% deles acreditam que publicações que apresentam RAGs são frequentes. Imagens em geral, e RAGs em especial, segundo 90\% dos entrevistados, atraem a atenção do leitor. 90\% dos entrevistados afirma ler os RAGs quando os encontra em alguma publicação científica. $63 \%$ acredita que o RAG auxilia o pesquisador na seleção de artigos acadêmicos para leitura e 64\% acredita que o RAG auxilia os editores de periódicos científicos a avaliarem artigos acadêmicos para publicação. No entanto, a maioria dos pesquisadores ouvidos (73\%) diz não acreditar que o RAG possa vir a substituir o RA. Para $64 \%$ dos entrevistados, os pesquisadores iniciantes não estão preparados para ler ou produzir um RAG. Quanto aos leitores não especialistas, 56\% dos entrevistados acredita que o RAG não desperta o desejo de ler o artigo acadêmico, enquanto $45 \%$ dos entrevistados acredita que os não especialistas podem ser atraídos para a leitura do artigo científico por meio do RAG.

Os entrevistados indicaram não haver consenso sobre o melhor termo para conceituar o RAG. De maneira geral, essa prática é definida como imagem, linguagem, resumo, forma gráfica, ferramenta, ilustração ou esquema "simples e conciso sobre as principais conclusões ou descobertas do artigo" (conf. informante da área de Biodiversidade), 
onde estão apontadas "as principais etapas do trabalho experimental". O RAG teria a função de "capturar, de forma imediata e eficiente, o olhar dos leitores para o conteúdo do artigo" (conf. informante da área de Biodiversidade) e otimizar o tempo de busca por artigos acadêmicos para leitura. Em geral, os pesquisadores entrevistados acreditam que o RAG deveria representar o objeto principal da pesquisa e as etapas metodológicas que culminaram nos resultados e conclusões obtidos. Notamos que o uso de setas é sugerido como forma de representar e ordenar a progressão das etapas da investigação. Em relação aos aspectos formais do RAG, os entrevistados demonstraram preocupação com a apresentação clara, concisa, nítida, organizada e lógica, de modo a priorizar "pontos mais importantes do trabalho que possam ser representados em figuras esquemáticas e de fácil interpretação" (conf. informante da área de Química). Não há consenso entre os pesquisadores sobre o público-alvo do RAG. De modo geral, a ênfase é dada a pesquisadores da área e "eventuais profissionais de outras áreas" (conf. informante da área de Biodiversidade). Quanto ao percurso de leitura do RAG, os entrevistados afirmaram buscar um "ponto principal de atenção" e a partir dele "observar como os elementos estão relacionados e os processos que essas relações representam (se houver)" (conf. informante da Biodiversidade). Alguns pesquisadores responderam que seguem as setas da imagem e, caso não existam setas, buscam se guiar pelo padrão de leitura ocidental: esquerda - direita; superior - inferior (KRESS; VAN LEEUWEN, 2006).

A análise documental realizada nos Sumários dos periódicos científicos e nas Instruções para autores de RAGs e as entrevistas realizadas com profissionais de Biodiversidade e de Química foram importantes para elucidar questões sobre o contexto de produção e de consumo dessa prática. Algumas dessas informações são especialmente relevantes para o estabelecimento da organização retórica de RAGs, conforme podemos observar no Quadro 1. 
QUADRO 1

Síntese dos resultados da análise contextual

\begin{tabular}{|l|l|l|}
\hline \multicolumn{1}{|c|}{ SUMÁRIOS } & \multicolumn{1}{|c|}{$\begin{array}{c}\text { INSTRUÇÕES PARA } \\
\text { AUTORES }\end{array}$} & \multicolumn{1}{c|}{ ENTREVISTAS } \\
\hline $\begin{array}{l}\text { Apresentam os RAGs } \\
\text { em destaque: natureza } \\
\text { publicitária, busca } \\
\text { atrair a atenção do } \\
\text { leitor. }\end{array}$ & $\begin{array}{l}\text { Instruções sobre a } \\
\text { materialidade e função do } \\
\text { RAG: sumarizar o tema e } \\
\text { as principais descobertas da } \\
\text { pesquisa; oferecem pistas } \\
\text { sobre a realização retórica } \\
\text { dos RAGs. }\end{array}$ & $\begin{array}{l}\text { Informam que o RAG: } \\
\text { - Atrai o leitor; } \\
\text { - Não substitui o RA; } \\
\text { - Apresenta as principais } \\
\text { conclu-sões e descobertas } \\
\text { do artigo acadêmico e as } \\
\text { etapas mais relevantes da } \\
\text { pesquisa. }\end{array}$ \\
\hline
\end{tabular}

Fonte: Elaborado pela autora

\subsection{O que o texto tem a informar sobre o RAG}

Para que pudéssemos compreender como as informações se conectam no RAG e quais funções retóricas realizam, analisamos os 40 RAGs que compõem o corpus textual desta pesquisa, descrevendo, incialmente, os significados representacionais, interativos e composicionais (KRESS; VAN LEEUWEN, 2006) do modo semiótico visual e, posteriormente, os significados ideacionais, interpessoais e textuais (HALLIDAY; MATTHIESSEN, 2004) do modo semiótico verbal. Para tanto, averiguamos se e como as categorias que constituem os sistemas de cada metafunção (Figura 1) se materializam. Os dados obtidos foram quantificados a fim de sistematizarmos os padrões visual e verbal em RAGs e, a partir do cruzamento dos dados da análise textual com aqueles da análise contextual, propor a organização retórica prototípica de RAGs de Química e de Biologia, conforme apresentamos a seguir.

\subsubsection{O que o modo semiótico visual tem a informar}

O RAG apresenta uma configuração predominantemente visual e complexa, formada por blocos visuais menores relacionados entre si e por blocos de texto (títulos, palavras, frases e labels), que promovem forte interação entre modo semiótico visual e verbal, conforme já vinha sendo apontado na literatura prévia (LEMKE, 1998; KRESS; VAN LEEUWEN, 
2006). Nesse sentido, adentramos nossos dados textuais determinando o número de imagens que compõem o complexo visual de cada um dos RAGs por meio da identificação de blocos visuais separados por algum tipo de espaçamento/moldura entre si.

Em termos representacionais (KRESS; VAN LEEUWEN, 2006), a análise de nossos dados textuais demonstrou que, em $65,5 \%$ de nossa amostra, as estruturas que constroem visualmente a natureza dos eventos, objetos e participantes envolvidos e as circunstâncias em que ocorrem são narrativas. As estruturas narrativas foram identificadas pela recorrência de dois padrões de realização dos vetores: i) interrimagem: realizados por setas pretas ou coloridas; e ii) intraimagem: realizados por setas coloridas, pretas ou participantes que formam vetores. Os vetores interrimagem ligam um bloco de informação a outro. Observamos que as setas pretas servem para ligar blocos de informação e passar a noção de progressão temporal dos eventos. As setas coloridas, estão ligadas a algum participante ou rótulo da imagem que está representado na mesma cor, demonstrando, assim, que aquele participante é o responsável pela progressão do processo representado ou dando destaque à progressão que ocorre em um momento específico do processo em que aquele participante está envolvido. Em alguns RAGs, as setas que configuram os vetores interrimagem são coloridas para dar destaque ao processo em si. Os vetores intraimagem auxiliam a narrar pequenos eventos que se unem a outros pequenos eventos por meio de vetores interrimagem e, assim, representam um evento narrativo maior. Há ainda, participantes que se tornam vetores intraimagem e que representam o avanço de uma ação no tempo.

Ainda no que concerne à metafunção representacional, 32,5\% de nossa amostra apresentou processos conceituais (KRESS; VAN LEEUWEN, 2006), revelando a essência ou classe dos participantes. Essas representações (classificacionais ou analíticas), também fazem parte de um complexo, pois em todos os casos de processos conceituais encontrados, há um processo narrativo subjacente (geralmente, marcado por vetores intraimagem) que direciona a compreensão de como a pesquisa resultou naquele conceito.

Nesse sentido, embora seja possível identificar estruturas predominantes, o que mais se destaca é o grau de complexificação visual (HENDGES; NASCIMENTO; MARQUES, 2013) dos RAGs, com estruturas subordinadas ou encaixadas (KRESS; VAN LEEUWEN, 
2006). Nesses termos, os RAGs podem ser definidos como unidades semânticas complexas (Figura 2), em que blocos representacionais menores (sejam narrativos ou conceituais) se ligam a outros núcleos informacionais por meio de vetores para representar uma ação maior ou se organizam de modo a representar um conceito principal.

FIGURA 2 - Metafunção representacional: processos principais e embutidos em RAGs

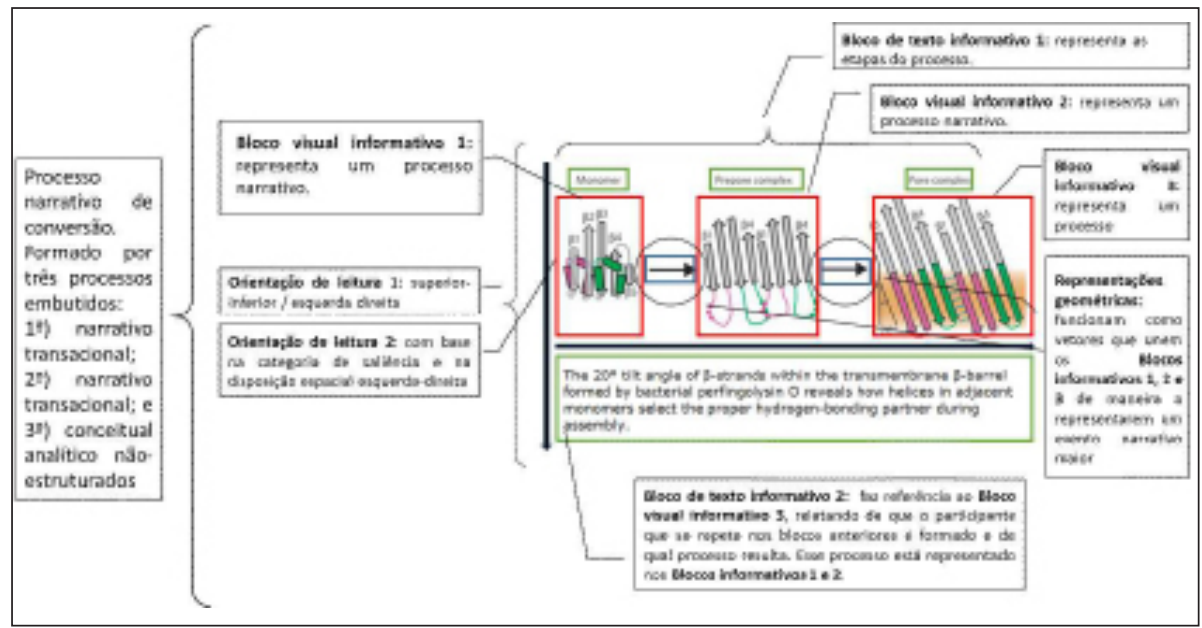

Fonte: esquematizado pela autora com base no RAG de Sato, Tweten e Johnson (2013) (grifos em vermelho, azul e verde nossos)

Notamos que os RAGs analisados pressupõem a existência de um participante interativo não-representado que seja minimamente especializado no assunto, pois os participantes e processos representados dependem de um agente externo que os interprete conforme os pressupostos e acordos simbólicos do campo científico. Dado o contexto em que os RAGs são produzidos e o seu conteúdo proposicional (conf. dados da análise do contexto), podemos sugerir que os participantes interativos sejam os pesquisadores de áreas análogas às áreas do RAGs. Observamos também que, do ponto de vista do processo principal que cada RAG representa, os blocos informativos configuram etapas da pesquisa científica, segundo os pressupostos do método científico (POPPER, 2005). As etapas mais recorrentemente apresentadas são metodologia e resultados, corroborando estudos sobre a sintetização da organização retórica prototípica do resumo acadêmico (SAMRAJ, 2005; 
AYERS, 2008; GOLEBIOWSKY, 2009), que inicialmente foi descrita como composta por Introdução-Metodologia-Resultados-Discussão (SWALES, 1990).

Levando em consideração que arranjos visuais reproduzem aspectos da realidade vinculados aos interesses das instituições sociais em que as imagens são produzidas, circuladas e lidas (KRESS; VAN LEEUWEN, 2006), a escolha por representar as etapas da pesquisa endossa alguns dos resultados obtidos na análise das entrevistas e corrobora constatações sobre a importância da evidência empírica e do emprego do raciocínio indutivo e hipotético-dedutivo na ciência contemporânea como sinais de respeitabilidade e da possibilidade de replicabilidade da descoberta científica (MCCOMAS, 2004). Além disso, nossos dados ratificam os dados de Bazerman (1988) e de Miller, T. (1998), demonstrado que as representações científicas, em geral, são abstratas, complexas e com forte carga teórica subjacente, por isso, de difícil acesso para leigos.

Conforme Kress e van Leeuwen (2006), os significados interativos expressam o tipo de interação estabelecida entre os participantes representados, os produtores da imagem e os espectadores das mensagens visuais. Esses significados se realizam por meio dos sistemas de: i) contato, cuja categoria de análise é o olhar; ii) distância social, cuja categoria de análise é o enquadramento; e iii) atitude, cuja categoria de análise é a perspectiva.

Os resultados da investigação da metafunção interativa demonstraram que em nosso corpus textual o contato é, em 100\% dos casos, realizado por meio da oferta, ou seja, os participantes representados são oferecidos ao leitor como "objetos de contemplação" (KRESS; VAN LEEUWEN, 2006, p. 119). Assim, a função desempenhada pelo participante interativo é de observador, enquanto o participante representado funciona como subsídio de alguma informação. Visto que, nos dados sobre a metafunção representacional, observamos que os participantes representados são etapas do método científico, então, é a pesquisa realizada que é dada para contemplação do leitor. Esses dados confirmam os dados de Kress e van Leeuwen (2006) sobre a preponderância da oferta em imagens da ciência. Além disso, revelam que os RAGs, embora sejam apresentados como elementos de um processo de mudança nas publicações científicas (ELSEVIER, 2009), replicam os parâmetros tradicionais de representação da ciência e de interação entre 
cientistas e leitores da ciência, pelo menos em algumas áreas (MOTTAROTH, 2006). Em termos de contato, a oferta de informação demonstra as relações de poder que se estabelecem entre o produtor do RAG e o leitor, uma vez que quem detém a informação, detém o poder.

Em termos representacionais, há predomínio de esquematizações de imagens impossíveis de serem vistas a olho nu, ou "transportadas diretamente do laboratório" (MILLER, 1998), capturadas por meio do uso de equipamentos especiais. Esse tipo de representação implica um enquadramento muito íntimo e, por consequência, um alto nível de abstração da representação. Conforme Kress e van Leeuwen (2006), esse tipo de enquadramento, de muito perto, sem contexto em torno da imagem, demonstraria que há uma interação entre leitor e participante representado. No entanto, pelo teor do conteúdo proposicional do RAG, conforme vimos na análise das entrevistas com pesquisadores e na análise da metafunção representacional, há uma limitação da audiência apta a decodificar as representações do RAG. Esses dados, endossam os dados de Mason, Morphet e Prosalendis (2006) sobre imagens da ciência, sugerindo que os RAGs promovem a interação entre participante(s) representado(s) e interativo(s) somente quando esses participantes compartilham de conhecimento contextual suficiente para interpretar e decodificar as convenções estabelecidas dentro da comunidade científica específica a qual pertencem.

Em relação à atitude, cuja categoria de análise é a perspectiva da imagem, 100\% das imagens são objetivas, ou seja, "revelam tudo que há para saber (ou que a imagem produzida tenha julgado necessário dar a saber) sobre os participantes representados" (KRESS; VAN LEEUWEN, 2006, p. 130). Esse resultado endossa os postulados de Kress e van Leeuwen (2006) sobre imagens da ciência, que seriam majoritariamente objetivas pelo caráter de imparcialidade que pretendem dar às informações representadas.

Nossos resultados revelaram, também, que 67,5\% dos RAGs investigados apresentam ângulo frontal. Segundo Kress e van Leeuwen (2006), em imagens objetivas, quando o ângulo é frontal, isto é, não há perspectiva, as representações são orientadas para a ação, como se dissessem "é assim que isso funciona" (KRESS; VAN LEEUWEN, 2006, p. 145). Em 32,5\% das amostras, o ângulo é perpendicular, indicando poder máximo e orientação para o conhecimento teórico (KRESS; VAN LEEUWEN, 2006). 
É interessante observar que os RAGs da área de Química apresentam equilíbrio entre ângulo frontal e perpendicular, apresentando $50 \%$ de amostras para cada tipo de ângulo. Já os RAGs interdisciplinares, apresentaram ângulo frontal em $85 \%$ da amostra e ângulo perpendicular em $15 \%$ da amostra. Esses resultados são relevantes, pois apoiam os resultados encontrados na análise da metafunção representacional, demonstrando que, em geral, os elementos visuais em RAGs buscam representar, além dos principais momentos e descobertas da pesquisa, a própria ação científica que é subjacente ao processo de pesquisa.

Devemos observar ainda, conforme relatamos anteriormente, que a divisão entre Química e Biologia possui linhas tênues, apresentando muito mais confluências entre as duas áreas do que divergências que permitiriam uma separação taxativa. Os periódicos científicos que apresentaram maior porcentagem de ângulo frontal são Nature Chemical Biology e Journal of Controlled Release, justamente os dois periódicos que, segundo nossa investigação, aparecem na interseção entre as áreas de Química e de Biodiversidade. Os periódicos científicos Angewendte Chemie e Energy and Environmental Science, que aparecem como representantes exclusivos da área de Química, apresentam, do ponto de vista do ângulo adotado na representação dos elementos visuais de seus RAGs, um equilíbrio entre a orientação para a ação (ângulo frontal) ou para o conhecimento (ângulo perpendicular). Considerando a recência da área de Biodiversidade (CAPES, 2011) sua característica multidisciplinar e a tradição da área de Química na produção de RAGs (NATURE, 2011), podemos inferir que para áreas mais consolidadas na prática de RAGs ou mais "puras", como a Química, a orientação para o conhecimento é mais facilmente realizada, enquanto para áreas em processo de consolidação e que apresentem interseções com outras áreas, como a Biodiversidade, a orientação para a ação é mais producente.

Quanto à Modalidade, considerando que suas categorias não são mensuráveis quantitativamente, apenas relativamente em uma escala que vai de um extremo ao outro da categoria, em um continuum (KRESS; VAN LEEUWEN, 2006), classificamos os dados da Modalidade em nosso corpus textual por meio da relativização da amostra. Assim, os resultados da análise da Modalidade revelam que a diferenciação da cor se faz presente em RAGs apenas quando essencial, mas é importante para distinguir participantes ou processos, produzindo no leitor impressões de clareza e confiabilidade sobre o que é representado. Por meio da 
diferenciação de cores é possível identificar os participantes de um processo e, visto que as representações visuais em RAGs são complexas, identificar um mesmo participante representado em outro momento do processo.

Conforme nossos resultados, a modulação e a saturação da cor são fracas em RAGs, provavelmente, porque esses elementos não são significativos para revelar experiências científicas. Nenhum dos 40 RAGs analisados apresenta contextualização, o que endossa que esses textos são escritos para um público especializado capaz de reconhecer os códigos de representação empregados para decodificar os significados do RAG sem o auxílio de um contexto. Os resultados da análise da representação em RAGs endossam as conclusões sobre a contextualização, pois, dos 40 RAGs da amostra, apenas 6 apresentam representação que mescla abstração máxima (nenhum vínculo com o mundo perceptível a olho nu) com representação mínima de detalhes visuais (algum tipo de vínculo com o mundo perceptível a olho nu). Todos os demais RAGs configuram representações abstratas, somente compreensíveis por alguém que domina o campo.

A profundidade é outro recurso da Modalidade pouco recorrente em elementos visuais de RAGs. A maioria dos RAGs da amostra (75\%) não apresenta profundidade. Considerando que a profundidade é um recurso que auxilia na representação visual e que imprime uma perspectiva ao que foi representado, é coerente que face à unanimidade de imagens objetivas em RAGs, a profundidade seja pouco explorada. Segundo nossa análise, a iluminação também não é um recurso recorrente em RAGs. O brilho é um recurso empregado em $25 \%$ dos RAGs de nossa amostra e somente quando essencial para chamar a atenção para um determinado participante ou para uma determinada etapa do processo. As cores escolhidas, em geral, são primárias (vermelho, amarelo e azul) e secundárias (laranjado, roxo e verde).

A título de exemplo do funcionamento dos significados interativos em RAGs, apresentamos a Figura 3, onde, em azul, procuramos mostrar realizações das categorias da metafunção interativa e, em verde, realizações das categorias da Modalidade. Como os RAGs são textos multimodais, observamos também como os recursos visuais da Modalidade realizam significados no modo semiótico verbal, que é unanimemente apresentado na cor preta, com uso da modulação para diferenciar títulos e pontos de maior ênfase. 
FIGURA 3 - Significados interativos em RAGs

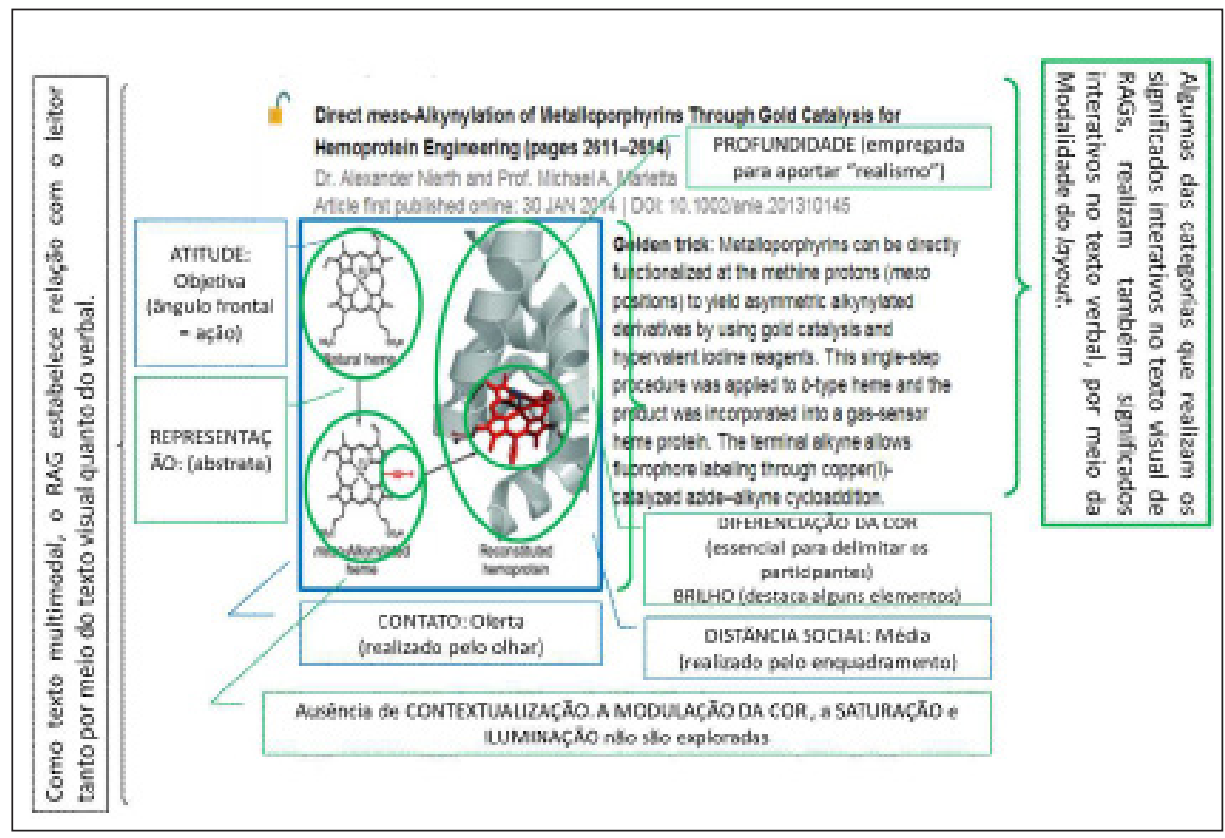

Fonte: esquematizado pela autora com base no RAG de Nierth e Marletta (2014).

Quanto aos significados composicionais, o mapeamento das informações materializadas pelos sistemas de valor da informação e de saliência contribuem para a compreensão de como a representação é organizada para atingir os seus propósitos comunicativos e estabelecer as relações interativas. Quanto à disposição espacial da informação, os resultados revelam que $57,5 \%$ dos RAGs possuem em sua composição imagens centradas, sendo a maioria destas (60\%) trípticas. $42,5 \%$ das imagens são polarizadas, sendo $70 \%$ delas compostas.

A predominância de trípticos e imagens polarizadas compostas em nossos resultados, nos leva a supor que, corroborando os resultados da análise representacional, os RAGs pretendem demonstrar os resultados da pesquisa científica realizada, à luz dos conceitos do método científico. Assim, imagens trípticas ou polarizadas compostas representariam as etapas principais da execução do método científico para cada pesquisa, ou as etapas melhor representáveis. 
Quanto à saliência, tomamos o modo semiótico visual como ponto de referência e definimos a imagem como simétrica ou assimétrica em relação ao centro do RAG e em relação ao modo semiótico verbal. Sendo assim, 75\% das imagens presentes nos RAGs do corpus textual são simétricas e $25 \%$ assimétricas. Esse dado demonstra que o modo semiótico visual em RAGs é destacado em relação ao modo semiótico verbal. Da mesma forma, o tamanho da imagem apoia essa conclusão. Dos 40 RAGs analisados, 34 (85\%) apresentaram o modo semiótico visual em tamanho maior em relação ao modo semiótico verbal. Quanto ao contraste, todas as imagens são coloridas, enquanto o texto verbal é preto, empregando apenas recursos de modulação da cor (metafunção interativa) para destacar títulos e palavras relevantes. Em todas as imagens que compõem os RAGs do corpus textual, o foco é nítido, imprimindo maior saliência para o modo semiótico visual. As imagens (100\%) são apresentadas em primeiro plano, demonstrando uma relação de igualdade entre os participantes e processos representados. A saturação da cor, se consideramos uma escala que vai da ausência total de cor à presença de saturação total, é intermediária. As cores, como vimos na análise da metafunção interativa, são, principalmente, primárias e secundárias e não exibem excessos de saturação, passando uma ideia de clareza da informação.

Quanto à molduragem, o RAG apresenta padrões bem claros. Existe um espaço destinado ao RAG (texto multimodal) no Sumário dos periódicos científicos e, dentro desse espaço, o modo semiótico verbal e o modo semiótico visual são, sem exceção (100\% dos casos) separados por uma moldura forte, normalmente, formada por espaços em branco antes e depois de cada modo semiótico. Os RAGs do periódico científico Journal of Controlled Release são os únicos que apresentam uma molduragem delimitada por um quadro com margens pouco saturadas. Na Figura 4, apresentamos um exemplo de análise da metafunção composicional em nosso corpus textual. 
FIGURA 4 - Significados composicionais em RAGs

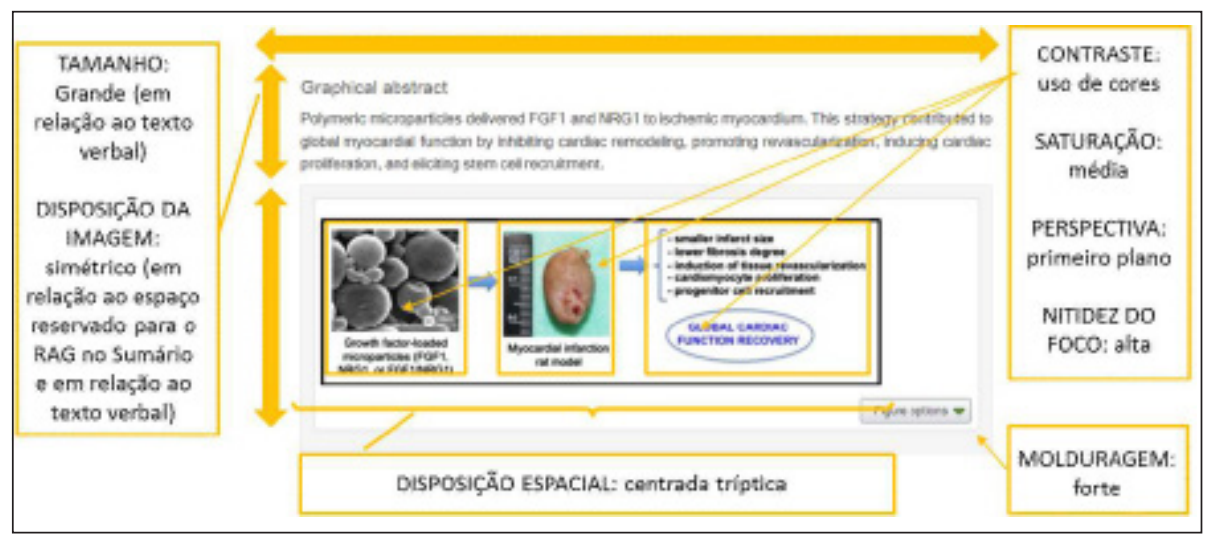

Fonte: esquematizado pela autora com base no RAG de Formiga et al. (2014)

Em síntese geral (Quadro 2), a análise metafuncional do modo semiótico visual de RAGs das áreas de Biodiversidade e de Química revelou a manutenção dos padrões de representação e de interação encontrados em estudos anteriores sobre imagens da ciência (BAZERMAN, 1988; MILLER, 1998). Em termos composicionais, o RAG apresenta como peculiaridade o fato de organizar as informações de modo a tornar visíveis as principais etapas do método científico. Algumas das informações obtidas por meio da análise do modo semiótico visual são especialmente relevantes para o estabelecimento da organização retórica de RAGs.

$$
\text { QUADRO } 2
$$

Síntese das informações da análise do modo semiótico visual de RAGs

\begin{tabular}{|l|l|l|}
\hline \multicolumn{1}{|c|}{$\begin{array}{c}\text { SIGNIFICADOS } \\
\text { REPRESENTACIONAIS }\end{array}$} & \multicolumn{1}{|c|}{$\begin{array}{c}\text { SIGNIFICADOS } \\
\text { INTERATIVOS }\end{array}$} & \multicolumn{1}{c|}{$\begin{array}{c}\text { SIGNIFICADOS } \\
\text { COMPOSICIONAIS }\end{array}$} \\
\hline $\begin{array}{l}\text { A identificação de } \\
\text { estruturas narrativas ou } \\
\text { conceituais encaixadas } \\
\text { ou subordinadas } \\
\text { contribui para a }\end{array}$ & $\begin{array}{l}\text { O emprego de cores } \\
\text { indica que o RAG } \\
\text { identificação espacial } \\
\text { tem a função de } \\
\text { movimentos retralizada no sumário, } \\
\text { a saliência em tamanho } \\
\text { e cor, o predomínio da } \\
\text { organização da informação } \\
\text { em trípticos revela como } \\
\text { os movimentos retóricos se } \\
\text { organizam. }\end{array}$ \\
\hline
\end{tabular}

Fonte: Elaborado pela autora 


\subsubsection{O que o modo semiótico verbal tem a informar}

A análise do modo semiótico verbal de RAGs revelou como as escolhas lexicogramaticais produzem significados ideacionais experienciais, interpessoais e textuais (HALLIDAY; MATTHIESSEN, 2004). Relatamos a seguir os dados mais relevantes para a proposição da organização retórica prototípica de RAGs a partir dessa análise.

A investigação do sistema de transitividade possibilitou a identificação de alguns dos movimentos retóricos representados por meios dos processos (Tabela 1).

\section{TABELA 1}

Processos mais frequentes no modo semiótico verbal de RAGs e as funções retóricas associadas

\begin{tabular}{ll}
\hline \multicolumn{1}{c}{ PROCESSOS } & MOVIMENTOS RETÓRICOS \\
\hline Investigar (2); estudar (2) & Apresentar a pesquisa \\
Sintetizar (2); usar (2) & Descrever metodologia \\
\hline $\begin{array}{l}\text { Mostrar (4); exibir (2); observar (2); } \\
\text { visualizar (2); revelar (4); observar (2); } \\
\text { melhorar (2) }\end{array}$ & Sumarizar resultados \\
\hline
\end{tabular}

Fonte: Elaborado pela autora

Em temos interpessoais, observamos, como já esperado, conforme a literatura prévia (HALLIDAY, MATTHIESSEN, 2004), ocorrência exclusiva de orações declarativas. Essas orações são usadas pelo participante autor do resumo para oferecer informações ao seu interlocutor a propósito da pesquisa relatada, expressando significados interpessoais relacionados ao seu julgamento pessoal. Por meio da modalização, o autor expressa graus de probabilidade ou de usualidade da informação. O texto compõe-se, portanto, de proposições que podem ser argumentadas, negadas, afirmadas ou colocadas em dúvida pelo interlocutor em função do caráter epistêmico de tais marcas linguísticas.

Nos blocos textuais que integram os RAGs analisados, observamos cinco casos de modalização de probabilidade (can) e um de usualidade (generally). Apesar de tais recursos não serem recorrentes, indicam que os autores do texto exploram os recursos da modalidade disponíveis no modo semiótico verbal para salientar o caráter refutável da pesquisa relatada. 
Durante a análise dos dados interpessoais, nos chamou atenção a frequência de marcas avaliativas. Nesse sentido, empregamos categorias analíticas de identificação de marcadores metadiscursivos interpessoais (KOPPLE, 1985; MORAES, 2005) para analisar nossa amostra. Segundo sistematização de Moraes (2005), os marcadores metadiscursivos interpessoais podem ser de posicionamento, dialógo e presença. Em nossos dados, houve exclusivamente casos de marcadores metadiscursivos de posicionamento, que podem ser atenuadores (quase, meramente, cerca de, talvez, p. ex.), enfatizadores (completamente, extremamente, muito, obviamente, p. ex.) e marcadores de atitude (curiosamente, felizmente, amplamente, significativamente, p. ex.) (MORAES, 2005).

Nossa análise revelou predomínio de marcadores de atitude (60\%), seguidos pelos enfatizadores (31\%), e pelos atenuadores $(9 \%)$. Esses dados demonstram o aspecto subjetivo que permeia o fazer científico, conforme demonstrado por Bazerman (1988), e ratificam a escolha de recursos verbais para a efetivação de tais significados.

Quanto aos significados textuais, observamos a predominância de tema não-marcado. Somente dois RAGs apresentaram tema marcado textual (presença de but e however). A quase ausência de temas textuais nos leva a supor que a compreensão do modo semiótico verbal em RAGs ocorre no nível do conteúdo. Esse dado é importante, pois descarta a especulação de que o RAG seja um resumo acadêmico ilustrado ou de que o modo semiótico verbal possa ser compreendido sem o auxílio do modo semiótico visual e vice-versa. Observamos que o modo semiótico verbal, geralmente, apresenta orações sintéticas, distribuídas em um único período. Essas orações funcionam como legendas que oferecem informações adicionais sobre a representação visual. Em geral, informações de difícil codificação por meio de recursos visuais.

Tendo como base a sequência de funções retóricas esperadas em resumos acadêmicos, conforme proposto por Motta-Roth e Hendges (2010), a saber: i) Situar a Pesquisa; ii) Apresentar a Pesquisa; iii) Descrever a Metodologia; iv) Sumarizar os Resultados; e v) Discutir a Pesquisa, a investigação do modo semiótico verbal de RAGs revelou predomínio das funções retóricas i, iii e iv. Além disso, a identificação de marcadores metadiscursivos de posicionamento demonstraram a função de atrair a atenção do leitor e destacar a pesquisa desenvolvida. 
A seguir, com base nos dados textuais e contextuais obtidos, apresentamos a organização retórica prototípica de RAGs de Química e de Biodiversidade.

\subsubsection{Organização retórica de RAGs}

Por entendermos, com base em Motta-Roth e Hendges (2010), que o movimento é uma função retórica mais ou menos fixa, materializada por subfunções que podem variar dentro de um mesmo gênero, a investigação da organização retórica de RAGs procurou identificar os principais movimentos e subfunções que compõem o RAG. Para o reconhecimento das funções retóricas, buscamos identificar e sistematizar pistas lexicais e de conteúdo presentes no RAG, com base nos dados fornecidos pela análise contextual e dos modos semióticos visual e verbal. Na Figura 5, apresentamos os resultados da investigação retórica que realizamos.

FIGURA 5 - Organização retórica prototípica de RAGs

\begin{tabular}{|c|c|c|c|}
\hline \multirow{4}{*}{$\begin{array}{l}\text { e/ou } \\
\text { e/ou }\end{array}$} & \multirow{2}{*}{$\begin{array}{l}\text { ORGANIZAÇÃO RETÓRICA DE RESUMOS ACADÊMICOS GRÁFICOS } \\
\text { MOVIMENTO } 1 \text { - POSICIONAR A PESQUISA (VE/VI) }\end{array}$} & Química & Biodiv. \\
\hline & & $100 \%$ & $100 \%$ \\
\hline & Subfunção 1A - Codificar verbalmente e visualmente o objeto de estudo (VE/VI).. & $100 \%$ & $100 \%$ \\
\hline & 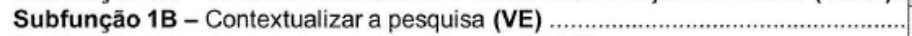 & $5 \%$ & $20 \%$ \\
\hline ou & Subfunção 1C - Caracterizar o objeto de estudo (VE) ....... & $15 \%$ & $15 \%$ \\
\hline ou & Subfunção 1D - Indicar lacunas em estudos prévios (VE) ......... & $5 \%$ & $0 \%$ \\
\hline & Subfunção 1E - Explicar a finalidade do objeto de estudo (VE) . & $10 \%$ & $0 \%$ \\
\hline & MOVIMENTO 2 - APRESENTAR O PROCESSO EXPERIMENTAL (VE/VI). & $100 \%$ & $100 \%$ \\
\hline e/ou & Subfunção 2A - Apresentar os principais passos metodológicos (VE/VI) .... & $100 \%$ & $100 \%$ \\
\hline e/ou & Subfunção 2B - Comparar a metodologia com metodologias prévias (VE). & $0 \%$ & $5 \%$ \\
\hline & 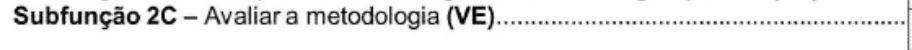 & $5 \%$ & $10 \%$ \\
\hline & MOVIMENTO 3 - EXPOR OS RESULTADOS (VE/VI) ............... & $100 \%$ & $100 \%$ \\
\hline e/ou & Subfunção $3 \mathrm{~A}$ - Apresentar os principais resultados (VE/VI)........ & $100 \%$ & $100 \%$ \\
\hline e/ou & Subfunção 3B - Representar a interpretação dos resultados (VI) ................. & $25 \%$ & $25 \%$ \\
\hline e/ou & Subfunção 3C - Comparar os resultados com resultados anteriores (VE)... & $0 \%$ & $5 \%$ \\
\hline e/ou & $\begin{array}{l}\text { Subfunção 3D - Contextualizar os resultados (VE) } \\
\text { Subfuncão } 3 E\end{array}$ & $15 \%$ & $10 \%$ \\
\hline & & $0 \%$ & $20 \%$ \\
\hline
\end{tabular}

Fonte: Elaborado pela autora

Como podemos observar, os três movimentos retóricos obrigatórios em RAGs são realizados tanto visualmente (VI) quanto verbalmente (VE). Visualmente, o Movimento 1, Posicionar a pesquisa, é realizado pela codificação dos participantes representados por meio de recursos visuais como volume, saliência, uso de representações visuais consensuais em cada área, emprego de rótulo verbais. O Movimento 2, 
Apresentar o processo experimental, pode ser realizado narrativamente ou conceitualmente. Quando o processo principal é narrativo, vetores intraimagem materializam mudança de estado em uma etapa da pesquisa e/ou vetores interrimagem indicam mudança de estado entre etapas da pesquisa. Quando o processo principal é conceitual, os participantes são organizados numa relação de parte-todo ou numa relação de tipos de. Não podemos deixar de salientar que esses modos de representação podem estar combinados em um único RAG, havendo predomínio de um deles. O Movimento 3, Expor os resultados, pode se materializar pelo emprego de diferentes recursos visuais: apresentação de dados crus (uma imagem de Raio X, p. ex.), gráficos, justaposição de imagens em sequência lógica (com ou sem uso de vetores), emprego de rótulos verbais.

Verbalmente, o Movimento 1, Posicionar a pesquisa, pode se materializar por meio de sentenças que contextualizam a pesquisa e/ou caracterizam o objeto de estudo ou indicam lacunas em estudos prévios ou explicam a finalidade do objeto de estudo. O Movimento 2, Apresentar o processo experimental, pode se materializar por meio de sentenças que avaliam a metodologia e/ou comparam a metodologia com metodologias de estudos prévios e/ou descrevem os principais passos metodológicos. O Movimento 3, Expor os resultados, pode se materializar por meio de sentenças que descrevem os principais resultados ou avaliam os principais resultados ou comparam os resultados com resultados de pesquisas anteriores ou contextualizam os resultados.

O estudo da organização retórica do RAG evidencia que o modo semiótico visual enfatiza principalmente a metodologia e os resultados da pesquisa, conforme as convenções de representação de cada área, sem apresentar marcas de subjetividade, primando pela clareza, concisão e objetividade. O modo semiótico verbal, por sua vez, apresenta marcas subjetivas, pela ênfase na relevância da metodologia escolhida e/ou da importância dos resultados para o avanço da fronteira do conhecimento na área.

Exemplificamos a realização visual e verbal da organização retórica prototípica de RAGs das áreas de Biodiversidade e de Química na Figura 6. 
FIGURA 6 - Exemplo da realização verbal e visual dos movimentos retóricos prototípicos de RAGs (com base no RAG de LEVINSON; BOXER, 2014)

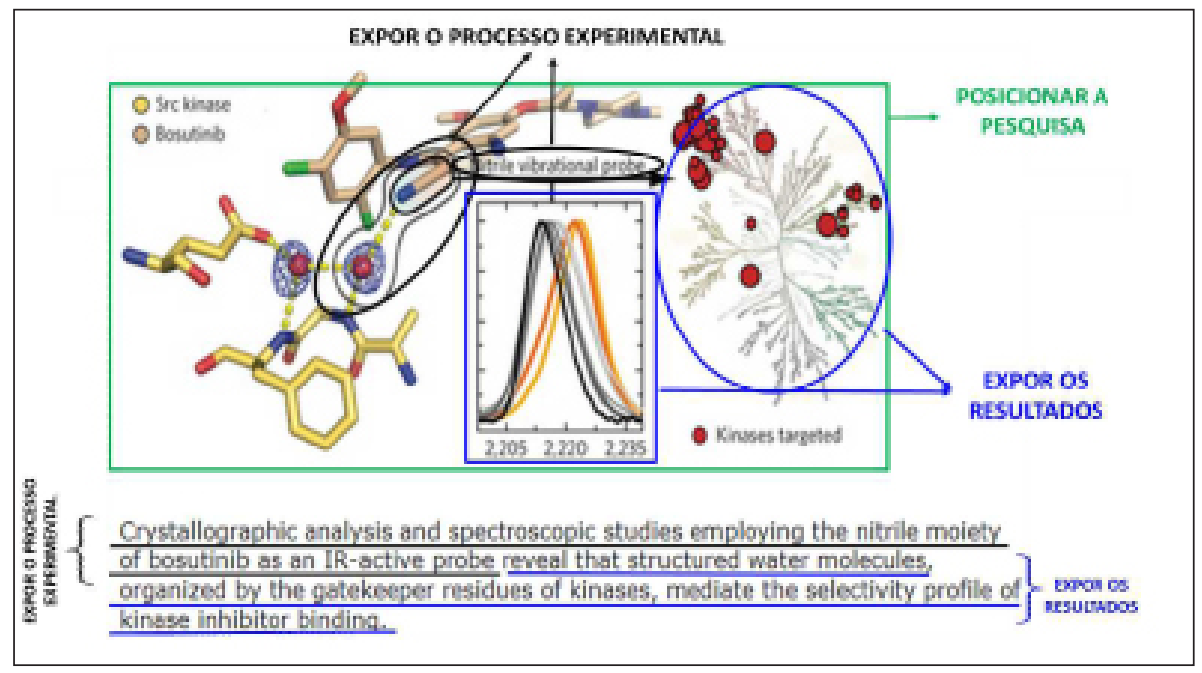

Fonte: Elaborado pela autora

\section{Considerações Finais}

À luz da ACG e de suas teorias fundantes, efetivamos a investigação contextual e textual do RAG. Esses dois níveis de análise revelaram que o RAG se diferencia do resumo acadêmico, gênero com o qual compartilha espaço nos Sumários dos periódicos científicos, tanto em termos de organização retórica quanto em termos de função. Isso significa que o(s) propósito(s) comunicativo(s) desses dois gêneros são diferentes, pelo menos em termos de propósito comunicativo principal. Segundo a literatura prévia (MOTTA-ROTH; HENDGES, 2010, p. 152), o propósito comunicativo principal do RA é "indicar e predizer, em um parágrafo curto, o conteúdo e a estrutura do texto integral que segue". O propósito comunicativo principal do RAG, segundo nossa investigação, é atrair a atenção do leitor, sumarizando a metodologia e os resultados da pesquisa, de maneira clara, concisa, positiva e persuasiva.

Conforme nossos resultados, a prática do RAG não dispensa a existência do RA. Pelo seu aspecto multimodal, o RAG explora ao máximo os recursos oferecidos pelos modos semióticos que o compõem 
para adequar-se aos demais gêneros do sistema de gêneros científicos e, ao mesmo tempo, acompanhar as mudanças no contexto em que se realiza, por exemplo, a necessidade de otimizar o tempo de leitura e de seleção de artigos acadêmicos, bem como, promover os resultados da pesquisa e adaptar-se às novas mídias de divulgação científica, como a Internet (conf. dados da análise contextual e de TENOPIR et al., 2013).

Especialmente por meio do modo semiótico visual, o RAG representa a ciência de forma a manter o caráter objetivo do discurso científico, o que lhe imprime confiabilidade. No entanto, por meio do modo semiótico verbal marcas de subjetividade são efetivadas no RAG, enfatizando sua característica principal: a atração do leitor por meio de uma representação positiva da pesquisa relatada.

Assim, à luz dos resultados que obtivemos podemos sugerir que o RAG é um novo gênero, que, seguindo a perspectiva de Todorov (2000), é a transformação de um gênero precedente, o RA, que já vinha apresentando variações em sua organização retórica (SAMRAJ, 2005; AYERS, 2008; GOLEBIOWSKI, 2009) no sentido de se tornar mais sintético e atrativo.

\section{Referências}

ASKEHAVE, I.; SWALES, J. M. Genre identification and communicative purpose: a problem and a possible solution. Applied Linguistics, Oxford University Press, v. 22, n. 2, p. 195-212, 2001.

AYERS, G. The evolutionary nature of genre: an investigation of the short texts accompanying research articles in the scientific journal Nature. English for Specific Purposes, Elsevier, v. 27, p. 22-41, 2008. Disponível em: <http://www.sciencedirect.com/science/article/pii/ S0889490607000221>. Acesso em: 12 set. 2016.

BAWARSHI, A. S.; REIFF, M. J. Gênero: história, teoria, pesquisa e ensino. SãoPaulo: Parábola, 2013.

BAZERMAN, C. Shaping written knowledge: the genre and activity of the experimental article in science. Madison: University of Wisconsin Press, 1988.

BHATIA, V. K. Analyzing genre: language use in professional settings. London: Longman, 1993. 
BHATIA, V. K. Worlds of written discourse: a genre-based view. London: Continuum, 2004.

CAPES. Sobre as áreas de avaliação. Governo Federal, 2014a. Disponível em: <http://www.capes.gov.br/avaliacao/sobre-as-areas-de-avaliacao>. Acesso em: 16 mar. 2016.

CAPES. Classificação da produção intelectual. Governo Federal, $2014 \mathrm{~b}$. Disponível em: <http://www.capes.gov.br/avaliacao/instrumentos-deapoio/classificacao-da-producao-intelectual>. Acesso em: 16 mar. 2016.

CAPES. Comunicado $n^{\circ}$ 002/2012. Área de Química: considerações sobre multidisciplinaridade e interdisciplinaridade na área, 2012. Disponível em: <http://www.capes.gov.br/images/stories/download/avaliacao/ Interdisciplinaridade_Quimica.pdf $>$. Acesso em: 5 mai. 2016.

CAPES. Comunicado $n^{\circ} 01 / 2011$. Área de Biodiversidade: a nova área de Biodiversidade na CAPES, 2011. Disponível em: $<$ http://www.capes. gov.br/images/07biodcomunicado01-2011.pdf $>$. Acesso em: 5 mai. 2016.

ELSEVIER B. V. Article of the future. 2009. Disponível em: <http:// www.elsevier.com/about/mission/innovative-tools/article-of-the-future>. Acesso em: 18 jul. 2013.

FAIRCLOUGH, N. Discourse and social change. Cambridge: Polity Press, 1992.

FAIRCLOUGH, N. Language and power. London: Longman, 1989.

FLOREK, C. S. Uma análise crítica de gênero de resumos acadêmicos gráficos. 2015. 240 p. Dissertação (Mestrado Estudos Linguísticos) Universidade Federal de Santa Maria, Santa Maria, 2015.

FLOREK, C.; HENDGES, G. R. Resumos acadêmicos gráficos: categorias e graus de especialização. Expressão, Santa Maria, v. 17, n. 2, p. 105-112, 2013.

FORMIGA, F. R. et al. Controlled delivery of fibroblast growth factor-1 and neuregulin-1 from biodegradable microparticles promotes cardiac repair in a rat myocardial infarction model through activation of endogenous regeneration. Journal of Controlled Release, Elsevier, v. 173, p. 132-139, 10 jan. 2014. Disponível em: $<$ http://www.sciencedirect. com/science/article/pii/S0168365913008833>. Acesso em: 12 mai. 2014. 
GOLEBIOWSKI, Z. Prominent messages in Education and Applied Linguistic abstracts: how do authors appeal to their prospective readers? Journal of Pragmatics, Elsevier, n. 41, p. 753-769, 2009. Disponível em: <http://www.sciencedirect.com/science/article/pii/ S0378216608002725>. Acesso em: 15 set. 2016.

HALLIDAY, M. A. K. An introduction to functional grammar. London: Edward Arnold, 1994.

HALLIDAY, M. A. K.; HASAN, R. Language, context, and text: aspects of language in a social-semiotic perspective. Oxford: Oxford University Press, 1989.

HALLIDAY, M. A. K.; MATTHIESSEN, C. M. I. M. An introduction to functional grammar. London: Edward Arnold, 2004.

HENDGES, G. R. Tackling genre classification: the case of HTML research articles. 2007. 209 f. Tese (Doutorado em Linguística Aplicada) - Universidade Federal de Santa Catarina, Florianópolis, 2007.

HENDGES, G. R.; NASCIMENTO, R. G.; MARQUES, P. M. A gramática da imagem como ferramenta na análise crítica de gêneros midiáticos. In: SEIXAS, L.; PINHEIRO, N. F. (Org.). Gêneros: um diálogo entre comunicação e Linguística Aplicada. Florianópolis: Insular, 2013. p. 241-274.

KNOX, J. Punctuating the home page: image as language in an online newspaper. Discourse \& communication, Los Angeles, v. 3, n. 2, p. 145$173,2009$.

KNOX, J. Visual-verbal communication on online newspaper home pages. Visual communications, London, v. 6, n. 1, p. 19-53, 2007.

KOPPLE, W. J. V. Some exploratory discourse on metadiscourse. College Composition and Communication, University of California, v. 36. n. 1, p. 82-83, 1985. Disponível em: <http://www.jstor.org/stable/357609>. Acesso em: 15 set. 2016.

KRESS, G.; VAN LEEUWEN, T. Reading images: the grammar of visual design. New York: Routledge, 1996.

KRESS, G.; VAN LEEUWEN, T. Reading images: the grammar of visual design. London: Routledge, 2006. 
LANE, S.; KARATSOLIS, A.; BUI, L. Graphical abstracts: a taxonomy and critique of an emerging genre. SIGEDOC, Limerick, Ireland, v. 1617, July 2015.

LEMKE, J. Multimedia genres for science education and scientific literacy. In: SCHLEPPEGRELL, M.; COLOMBI, M. C. (Ed.). Developing advanced literacy in first and second languages. Mahwah: Erlbaum, 2002. p. 21-44.

LEMKE, J. Multiplying meaning: visual and verbal semiotics in scientific text. In: MARTIN, J. R.; VEEL, R. (Ed.). Reading science. London: Routledge, 1998. p. 87-113.

LEVINSON, N. M; BOXER, S. G. A conserved water-mediated hydrogen bond network defines bosutinib's kinase selectivity. Nature Chemical Biology, v. 10, n. 2, p. 127-132, dez. 2014. Disponível em: <http://www. nature.com/nchembio/journal/v10/n2/index.html>. Acesso em: 9 mai. 2014.

MASON, R.; MORPHET, T.; PROSALENDIS, S. Reading scientific images: the iconography of evolution. Cape Town: HSRC Press, 2006.

MCCOMAS, W. F. Keys to teaching the nature of science. The science teacher, v. 9, n. 71, p. 24-27, 2004. Disponível em: <http://www.nsta. org/publications/news/story.aspx? id=49929>. Acesso em: 15 set. 2016.

MEURER, J. L. Gêneros textuais na análise crítica de Fairclough. In: MEURER, J. L.; BONINI, A.; MOTTA-ROTH, D. (Ed.). Gêneros: teorias, métodos, debates. São Paulo: Parábola, 2005. p. 81-106.

MEURER, J. L. Uma dimensão crítica do estudo de gêneros textuais. In: MEURER, J. L.; MOTTA-ROTH, D. (Org.). Gêneros textuais e práticas discursivas: subsídios para o ensino da linguagem. Bauru: EDUSC, 2002. p. 17-29.

MILLER, C. Genre as social action. Quarterly Journal of Speech, Taylor \& Francis Online, v. 70, p. 157-78, 1984. Disponível em: <http://www. tandfonline.com/doi/abs/10.1080/00335638409383686>. Acesso em: 15 set. 2016.

MILLER, T. Visual persuasion: a comparison of visuals in academic texts and the popular press. English for Specific Purposes, Elsevier, v. 17, n. 1, p. 29-46, 1998. Disponível em: < http://www.sciencedirect.com/science/ article/pii/S088949069700029X>. Acesso em: 15 set. 2016. 
MOITA LOPES, L. P. (Org.). Por uma linguística aplicada indisciplinar. São Paulo: Parábola, 2006.

MOITA LOPES, L. P. Da aplicação da linguística à linguística aplicada indisciplinar. In: PEREIRA, R. C.; ROCA, P. Linguística aplicada: um caminho com diferentes acessos. São Paulo: Contexto, 2011. p. 11-24.

MORAES, L. S. B. O metadiscurso em artigos acadêmicos: variação intercultural, interdisciplinar e retórica. 2005. 194f. Tese (Doutorado em Letras). Pontifícia Universidade Católica do Rio de Janeiro, Rio de Janeiro-RJ, 2005.

MOTTA-ROTH, D. A dinâmica de produção de conhecimento: teorias e dados, pesquisador e pesquisados. Revista Brasileira de Linguística Aplicada, Belo Horizonte, v. 3, n. 1, p. 165-184, 2003. doi.org/10.1590/ S1984-63982003000100011

MOTTA-ROTH, D. Analise crítica de gêneros: contribuições para o ensino e a pesquisa de linguagem. DELTA, São Paulo, v. 24, p. 341-383, 2008. doi.org/10.1590/s0102-44502008000200007

MOTTA-ROTH, D. Questões de metodologia em análise de gêneros. In: KARWOSKI, A.; GAYDECZKA, B.; BRITO, K. S. (Org.). Gêneros textuais: reflexões e ensino. União da Vitória-PR: Editora Kaygangue, 2006. p. 179-202.

MOTTA-ROTH, D.; HENDGES, G. R. Produção textual na universidade. São Paulo: Parábola Editorial, 2010.

MYERS, G. Writing biology: texts in the social construction of scientific knowledge. Madison: University of Wisconsin Press, 1990.

NATURE. The art of abstracts, v. 3, n. 571, Aug. 2011. Disponível em: <http://www.nature.com/nchem/journal/v3/n8/full/nchem.1109. html? ?T.feed_name $=$ subjects_chemistry-publishing $>$. Acesso em: maio 2012.

NIERTH, A.; MARLETTA, M. A. Direct meso-Alkynylation of Metalloporphyrins Through Gold Catalysis for Hemoprotein Engineering. Angewandte Chemie, Wiley Online Library, v. 53, n. 10, p. 2611-2614, mar. 2014. Disponível em: <http://onlinelibrary.wiley.com/doi/10.1002/ anie.v53.10/issuetoc $>$. Acesso em: 12 mai. 2014. 
O’HALLORAN, K. L. Introduction. In: O’HALLORAN, K. L (Ed.). Multimodal discourse analysis: systemic functional perspectives. London; New York: Continuum, 2004. p. 1-7.

O'TOOLE, M. The language of displayed art. Leicester: Leicester University Press, 1994.

PÉREZ-LLANTADA, C. The article of the future: strategies for genre stability and change. English for specific purposes, Elsevier, v. 32, p. 221-235, 2013. Disponível em: < http://www.sciencedirect.com/science/ article/pii/S0889490613000422>. Acesso em 15 set. 2016.

POPPER, K. The logic of scientific discovery. London; New York: Routledge, 2005.

PRPGP/UFSM. Catálogo cursos de pós-graduação UFSM, 2013. Disponível em: <http://prpgp.ufsm.br/images/diversos/CATALOGOPG-UFSM-2013.pdf>. Acesso em: 13 set. 2016.

SAMRAJ, B. An exploration of a genre set: research article abstracts and introductions in two disciplines. English for specific purposes, Elsevier, v. 24, n. 2, p. 141-156, 2005.

SATO, T. K.; TWETEN, R. K.; JOHNSON, A. disulfide-bond scanning reveals assembly state and $\mathrm{b}$-strand tilt angle of the $\mathrm{pFO} b$-barrel. Nature Chemical Biology, Macmillan Publishers Limited, v. 9, n. 6, p. 383-389, abr. 2013. Disponível em: <http://www.nature.com/nchembio/journal/ v9/n6/index.html>. Acesso em: 9 mai. 2014.

SNOW, C. P. As duas culturas e uma segunda leitura: uma versão ampliada das duas culturas e a revolução científica. São Paulo: EDUSP, 1995.

SWALES, J. M. Genre analysis: English in academic and research settings. Cambridge: Cambridge University Press, 1990.

SWALES, J. M. Research genres: explorations and applications. New York: Cambridge University Press, 2004. doi.org/10.1017/ CBO9781139524827

TENOPIR, C. et al. Trust and authority in scholarly communications in the light of digital transition: final report. Knoxville, USA: University of Tennessee USA; Greenham, UK: CIBER Research, 2013. 
THE NEW LONDON GROUP. A pedagogy of multiliteracies: designing social futures. Harvard Educational Review, Spring Research Library, v. 1, n. 66, p. 60-92, 1996.

TODOROV, T. The origin of genres: modern genre theory. New York: Longman, 2000.

UNSWORTH, L. Teaching multiliteracies across the curriculum. Philadelphia: Open University Press, 2001.

VAN LEEUWEN, T. Discourse and practice: new tools for Critical Discourse Analysis. New York: Oxford University Press, 2008. doi. org/10.1093/acprof:oso/9780195323306.001.0001

VAN LEEUWEN, T. Genre and field in critical discourse analysis. Discourse \& society, Sage Publications, v. 4, n. 2, p. 193-223, 1993. Disponível em: $<\mathrm{http}: / /$ das.sagepub.com/content/4/2/193.full.pdf + html $>$. Acesso em: 15 set. 2016.

WEB OF KNOWLEDGE. Journal Citation Reports, 2016. Disponível em: $<$ http://admin.webofknowledge.com/SessionError.cgi?CSID=\&Dest App $=\mathrm{JCR} \&$ Error $=\mathrm{SESSION}+\mathrm{NOT}+\mathrm{ACTIVE}>$. Acesso em: 2 mai. 2016. 